\title{
Erratum: Demographic and socio-economic predictors of physical activity among people living with HIV of low socio-economic status
}

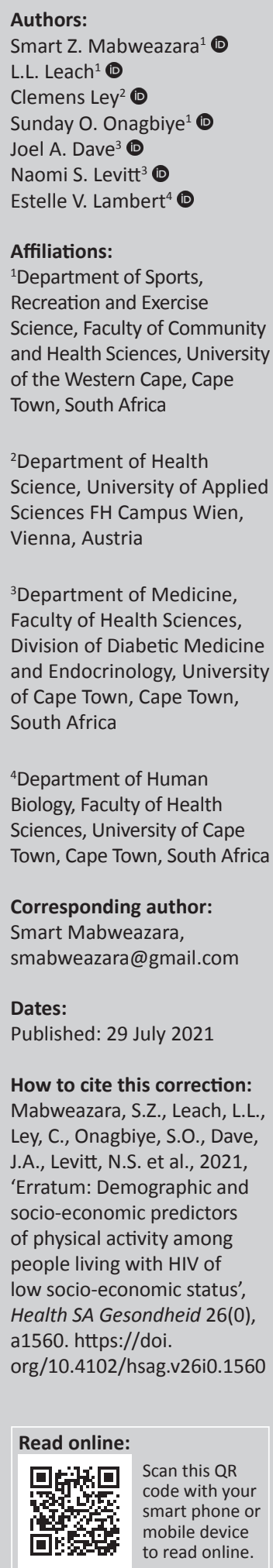

In the version of this article initially published, Mabweazara, S.Z., Leach, L.L., Ley, C., Onagbiye, S.O., Dave, J.A., Levitt, N.S. et al., 2019, ‘Demographic and socio-economic predictors of physical activity among people living with HIV of low socio-economic status', Health SA Gesondheid 24(0), a1127. https://doi.org/10.4102/hsag.v24i0.1127, the third author's affiliation was given incorrectly. The correct affiliation should be 'Department of Health Science, University of Applied Sciences FH Campus Wien, Vienna, Austria' instead of 'Department of Health Science, University of Applied Sciences, Vienna, Austria'.

This correction does not alter the study's findings of significance or overall interpretation of the study's results. The publisher apologises for any inconvenience caused.

Copyright: (c) 2021. The Authors. Licensee: AOSIS. This work is licensed under the Creative Commons Attribution License. Note: DOI of original article published: https://doi.org/10.4102/hsag.v24i0.1127 